www.jmscr.igmpublication.org

Impact Factor (SJIF): 6.379

Index Copernicus Value: 71.58

ISSN (e)-2347-176x ISSN (p) 2455-0450

crossrefDOI: https://dx.doi.org/10.18535/jmscr/v6i6.170

Journal Of Medical Science And Clinical Research

\title{
A Study of Morphology and Histopathology of Ligature Marks in Asphyxial Deaths by Compression of Neck in Jodhpur Region, Rajasthan
}

\author{
Authors \\ Dr Navneet Sharma ${ }^{1}$, Dr Amit Shrivastava ${ }^{2 *}$, Dr P.C. Vyas ${ }^{3}$ \\ ${ }^{1}$ IIIYear Resident, ${ }^{2}$ Senior Resident, ${ }^{3}$ Senior Professor\& Head \\ Department of Forensic Medicine, Dr. S. N. Medical College, Jodhpur, India \\ *Corresponding Author \\ Dr Amit Shrivastava \\ Email:dramitmlc2014@gmail.com
}

\begin{abstract}
Introduction: The ligature mark is vital piece of evidence in asphyxia deaths. There has been extensive study about external appearance of asphyxia deaths due to hanging and ligature strangulation but histopathological study of the neck structures in these cases are very few. In this study an attempt has been made to establish the most reliable morphological and histopathological features for differentiating the pattern of ligature mark in cases of asphyxial deaths.

Materials and Methods: Hospital based observational study was carried out at a tertiary care teaching hospital of western Rajasthan over a period of one year. Total 104 cases of hanging and strangulation were taken for study. Details about morphological findings of ligature mark were noted and tissue section including samples of skin, subcutaneous tissue, muscles, thyrohyoid complex and cervical lymph nodes from neck beneath the ligature mark were dissected out and sent in 10\% formalin for histopathological examination.

Results: Common morphological findings of ligature mark in hanging were single (91\%), atypical (89\%), discontinuity of ligature mark (98\%), incomplete encirclement (98\%), oblique mark (100\%), Parchmentisation (56\%), Reddish-browncolour (23\%), pale (21\%) while in ligature strangulation these were single (50\%), multiple (50\%), discontinuity of ligature mark (25\%), complete encirclement (75\%), transverse (75\%), Parchmentisation (50\%), Reddish-browncolour (50\%), extravasation of blood (100\%). Common histopathological findings of ligature mark in hanging were abraded epidermis (38\%), dermal congestion (48\%), muscle hemorrhage (37\%), muscle necrosis (7\%), muscle autolysis (9\%), perifollicular congestion (23\%), perifollicular hemorrhage (7\%), congestion of lymph node (21\%)while in ligature strangulation these were dermal hemorrhage (75\%), dermal congestion (25\%), muscle hemorrhage (75\%) muscle necrosis $(25 \%)$, perifollicular hemorrhage $(75 \%)$ and congestion of lymph node $(100 \%)$.

Conclusion: The present study concluded that a detailed evaluation of the gross and histopathological findings of the ligature mark, if undertaken would be more conclusive in establishing the cause and manner of death to aid in the administration of justice.

Keywords: Asphyxial deaths, hanging, strangulation, ligature mark, morphology, histopathology.
\end{abstract}




\section{Introduction}

Asphyxia is a term derived from Greek that literally translates as "stopping of the pulse." Asphyxia is caused due to interference in the uptake or release of oxygen. Asphyxial deaths are one of the most common homicidal and suicidal deaths. Mechanical asphyxia is most commonly encountered type in medico legal practice. Among the means of producing mechanical asphyxia, constriction around the neck plays a major role. Different types of asphyxial deaths include hanging, ligature strangulation, burking and drowning. ${ }^{[1]}$

Hanging is one of the most common methods of suicide in India; other types of hangings are homicidal hanging, judicial hanging, and autoerotic hanging. ${ }^{[1]}$ Various forms of strangulations are ligature strangulation, throttling, mugging, garrotting, bansdola etc. The characteristic findings, the ligature mark found around the neck in both hanging and strangulation create an element of doubt in many cases. The difficulty increases many folds when one has to differentiate ligature mark of homicidal hanging from strangulation as associated bodily injuries are found on both occasions, though in suicidal hangings it may be difficult due to absence of marks of violence and resistance. ${ }^{[2]}$

The ligature mark is an important finding when actual ligature is not available. The most important findings of ligature marks are; level, discontinuities and obliquity, which may differentiate hanging from ligature strangulation. There has been extensive study about external appearance of asphyxia deaths due to hanging and ligature strangulation but histopathological study of the neck structures in these cases are very few.Role of histopathological examination is two folds; First, it may produce a scientific corroboration of circumstantial evidence and gross findings. Secondly, it may help to determine whether changes seen grossly are ante mortem or post-mortem. ${ }^{[3,4]}$

The present study was planned to establish the most reliable morphological features for differentiating the pattern of ligature mark in cases of asphyxial deaths due to compression of neck by ligature in hanging and ligature strangulation along with the analysis of the histopathological findings.

\section{Materials and Methods}

It was a hospital based observational study, carried out at Department of Forensic Medicine and Department of Pathology, Dr. S. N. Medical College, Jodhpur (Rajasthan). The study period was one year from $1^{\text {st }}$ January 2017 to $31^{\text {st }}$ December 2017. Approval from institutional ethics committee was taken and all compatible autopsies of hanging and ligature strangulation received during study period were included in the study. Highly decomposed and charred burnt bodies were excluded from the study. Detailed and complete external examination of the body was carried out along with dimensions of ligature mark, neck circumference and site of ligature mark, its pattern and other morphological features. Routine instrument and material of dissection were used for internal examination of body.

The neck structures were dissected to study the pathology caused by compression underneath the ligature mark. The dissection was done in layers i.e. skin and subcutaneous tissue, muscles of neck, thyrohyoid complex, trachea and larynx. Any fracture of the thyrohyoid complex was noted, appropriate tissue section including samples of skin and subcutaneous tissue, muscles, thyrohyoid complex and cervical lymph nodes from neck beneath the ligature mark were dissected and preserved in 10\% formalin solution for histopathological examination. Routine "Hematoxylin and Eosin" stain was used.Tissue samples were taken from 5 normal cases for comparison as a control.

\section{Results}

During this period, a total number of 104 cases were observed in hanging and ligature strangulation, brought for post-mortem 
examination through various police stations of Jodhpur city. Out of 104 cases, 100 cases were of hanging (all suicidal), and 4 cases were of ligature strangulation, in which 3 cases were homicidal and 1 case was accidental. The maximum number of cases were found in age group 21 to 30 years (46 cases, $44.23 \%$ ) followed by 31 to 40 years (29 cases, $27.88 \%$ ) and then age group 11 to 20 years (16 cases, 15.38\%). Minimum age to commit hanging was a 16 years male in this study. 71 cases $(68.27 \%)$ males and 29 cases $(27.88 \%)$ females had committed suicide by hanging with male: female ratio of 2.45:1. The ligature strangulation was observed equally in females and males (50\% each).

As shown in figure-1 cotton rope was exclusively used for hanging in 51\% cases followed by chunni (33\%) and sari (5\%). Out of 3 cases of homicidal ligature strangulation nylon rope was used in 2 cases and cotton rope in 1 case. Cotton rope has compressed the neck in 1 case of accidental ligature strangulation. Fixed knot were found in $96 \%$ cases of hanging while slip knot were found in $4 \%$ cases. Slip knot was detected as revealed during police investigation in all the 4 cases of ligature strangulation.

Atypical (88\%) and complete (88\%) type of hanging was predominant to typical $(12 \%)$ and partial (12\%) type of hanging. As per information gathered from the police inquest officers, relatives and findings on the neck, single ligature mark was found in $91 \%$ cases of hanging followed by multiple marks (9\%) while in the ligature strangulation single mark was found in 2 $(50 \%)$ cases and multiple marks found in $2(50 \%)$ cases. In most of the cases of hanging, ligature impression was found at above the thyroid cartilage level (98\%) cases and followed by on the level of thyroid cartilage (2\%) cases and in none of the case ligature mark was found below thyroid cartilage level while in ligature strangulation in $3(75 \%)$ cases the ligature impression was found on the thyroid cartilage level and in $1(25 \%)$ case it was situated below thyroid cartilage level. The discontinuity of ligature mark was observed in almost all (98\%) cases of hanging irrespective of their typical/ atypical type or complete/ partial type and it was absent in $3(75 \%)$ cases of ligature strangulation. The features of the mechanical cutaneous alteration and color changes were observed in the study. It was found that reddish brown color of ligature mark was seen in $23(23 \%)$ cases, it was anemic pale in $21(21 \%)$ cases and Parchmentisation was occurred in $56(56 \%)$ cases of hanging while in ligature strangulation reddish brown colour of ligature mark was seen in 2 (50\%) cases and Parchmentisation was seen in 2 $(50 \%)$ cases of ligature strangulation. The pale white anemic appearance of ligature mark was found in $100 \%$ cases of hanging while extravasations of blood present in all the 4 $(100 \%)$ case of ligature strangulation who succumbed to death (Table-1).

The skin under the ligature mark was also studied histopathologicaly for the mechanical cutaneous alterations. Abrasion of epidermis was detected in 35 (35\%) cases and dermal congestion was detected in $48(48 \%)$ cases of hanging while among cases of ligature strangulation dermal hemorrhage was frequent finding which was found in the $3(75 \%)$ cases of ligature strangulation. While observing the musculature of the neck under the ligature mark, mostly the hemorrhages in the ribbon muscles of neck was found in $37(37 \%)$ cases of hanging and in 3 $(75 \%)$ cases ligature strangulation. The necrosis of the muscles was also associated feature in these cases and as the post-mortem interval increases, the feature of autolysis supervenes. In case of hanging where the ligature mark was found over the thyroid cartilage, perifollicular congestion was commonly found in 23 (23\%) cases where as in ligature strangulation perifollicular hemorrhage were detected in 4 $(100 \%)$ cases. Histopathological findings of cervical lymph node showed the congestion in 21 (21\%) cases of hanging and $4(100 \%)$ cases of ligature strangulation. Sub capsular hemorrhage was found in 9 (9\%) cases of hanging (Table-2). 


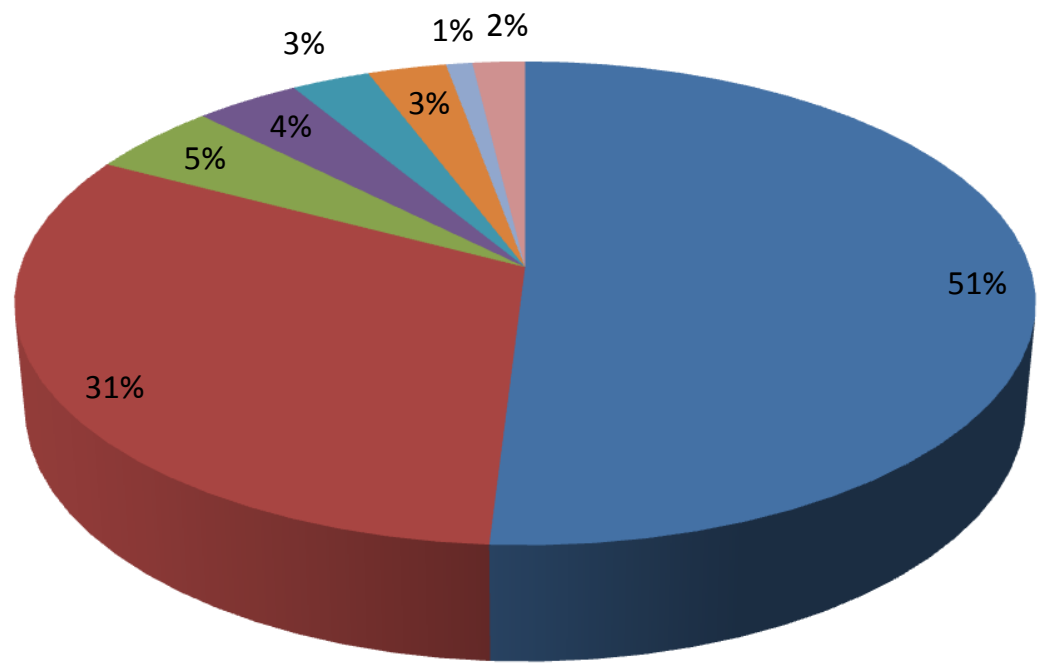

- Cotton rope

- Chunni

- Sari

Nylon rope

Plastic rope

Lungi

Bed sheet

niwar

Figure-1: Distribution of cases according to ligature material

Table-1: Morphological findings of ligature mark in hanging and strangulation

\begin{tabular}{|l|c|c|c|}
\hline \multicolumn{2}{|c|}{ Morphological Parameter } & $\begin{array}{c}\text { Hanging } \\
\mathbf{n}(\%)\end{array}$ & $\begin{array}{c}\text { Strangulation } \\
\mathbf{n}(\%)\end{array}$ \\
\hline \multirow{3}{*}{ Number of Turns } & Single & $91(91 \%)$ & $2(50 \%)$ \\
\cline { 2 - 4 } & Multiple & $9(9 \%)$ & $2(50 \%)$ \\
\hline \multirow{3}{*}{ Level of ligature mark } & Above thyroid cartilage & $98(98 \%)$ & $0(0 \%)$ \\
\cline { 2 - 4 } & On thyroid cartilage & $2(2 \%)$ & $3(75 \%)$ \\
\cline { 2 - 4 } & Below thyroid cartilage & $0(0 \%)$ & $1(25 \%)$ \\
\hline \multirow{2}{*}{\begin{tabular}{l} 
Discontinuity of the ligature \\
\cline { 2 - 4 }
\end{tabular}} & Present & $98(98 \%)$ & $1(25 \%)$ \\
\hline \multirow{2}{*}{\begin{tabular}{l} 
Cutaneous alteration textures) \\
\cline { 2 - 4 }
\end{tabular}} & Absent & $2(2 \%)$ & $3(75 \%)$ \\
\cline { 2 - 4 } & Peddish-brown & $23(23 \%)$ & $2(50 \%)$ \\
\hline \multirow{2}{*}{ Internal appearance } & Pale & $21(21 \%)$ & $0(0 \%)$ \\
\cline { 2 - 4 } & Pale White & $100(100 \%)$ & $0(0 \%)$ \\
\hline
\end{tabular}


Table-2: Histopathological findings of ligature mark in hanging and strangulation

\begin{tabular}{|l|c|c|c|}
\hline \multicolumn{2}{|c|}{ Parameter } & $\begin{array}{c}\text { Hanging } \\
\mathbf{n}(\mathbf{\%})\end{array}$ & $\begin{array}{c}\text { Strangulation } \\
\mathbf{n}(\mathbf{\%})\end{array}$ \\
\hline \multirow{4}{*}{ Skin findings } & Abraded epidermis & $35(35 \%)$ & $0(0 \%)$ \\
\cline { 2 - 4 } & Dermal congestion & $48(48 \%)$ & $1(25 \%)$ \\
\cline { 2 - 4 } & Dermal hemorrhage & $0(0 \%)$ & $3(75 \%)$ \\
\cline { 2 - 4 } Skin findings & Hemorrhage & $37(37 \%)$ & $3(75 \%)$ \\
\hline \multirow{4}{*}{ Thyroid gland findings } & Necrosis & $7(7 \%)$ & $1(25 \%)$ \\
\cline { 2 - 4 } & Autolysis & $9(9 \%)$ & $0(0 \%)$ \\
\cline { 2 - 4 } & Perifollicular congestion & $23(23 \%)$ & $0(0 \%)$ \\
\cline { 2 - 4 } & Perifollicularhemorrhage & $7(7 \%)$ & $4(100 \%)$ \\
\cline { 2 - 4 } & Necrosis & $7(7 \%)$ & $0(0 \%)$ \\
\hline \multirow{4}{*}{ Cervical lymph node findings } & Autolysis & $8(8 \%)$ & $0(0 \%)$ \\
\cline { 2 - 4 } & Capsular/ subcapsular hemorrhage & $9(9 \%)$ & $4(100 \%)$ \\
\cline { 2 - 4 } & Congestion & $7(7 \%)$ & $0(0 \%)$ \\
\cline { 2 - 4 } & Necrosis & $8(8 \%)$ & $0(0 \%)$ \\
\hline
\end{tabular}

\section{Discussion}

In the present study the maximum number of cases who committed suicide by hanging were found in 21-30 years age group (44.23\%) followed by $31-40$ years $(27.88 \%)$. The observation were consistent with the studies of Monochand et al $(1998)^{[5]}$, Sheikh et al $1999^{[6]}$ and Joshi et al 2007. ${ }^{[7]}$ Cotton rope and chunni were commonly used in present study the for committing suicide by hanging because of cotton rope is easily available in Indian house hold and it also ensure that the act (compression of neck) will be successfully accomplished just like judicial hanging. Chunni is the common part of the dress of the female in Rajasthan and other part of North India. In previous study by Joshi et al $2007^{[7]}$ commonest ligature material was also rope (32.5\%), followed by Chunni (18.16\%) and Turban (11.6\%). Another study by Sheikh et al $1999^{[6]}$ commonest ligature material was nylon rope $(53.02 \%)$ followed by linen $(31.8 \%)$. In study by Sharma et a1 $(2005)^{[8]}$ commonest ligature material was Chunni $(30.90 \%)$ followed by nylon rope $(18.18 \%)$ cases, bed sheet $(16.36 \%)$ and jute rope $(12.73 \%)$.

In the present study atypical hanging was predominant to typical hanging and complete hanging was predominant to partial hanging and results were consistent with Naik at el (2005) ${ }^{[9]}$ and Jani et a1 (2002) ${ }^{[10]}$ who reported more cases of atypical hanging $(92.6 \%$ and $60.8 \%$ respectively) then typical hanging $(7.39 \%$ and $39.2 \%$ respectively). The higher incidence of atypical hanging can be explained on the basis of easy access of tying of knot on either side of the neck than the occipital region. Both the workers also reported that death due to complete hanging (93.53\% and $60.8 \%$ respectively) was more than partial hanging $(6.47 \%$ and $39.2 \%$ respectively) which can be explained due to belief that it would ensure death just like judicial hanging.

Present study suggests that single mark was more common than multiple marks in cases of hanging while reverse was found in case of ligature strangulation. This was probably due to the fact that the multiple turns of the ligature are applied by the assailant so that the victim should surely be killed and it also indicates the aggressiveness and intention of the assailant. All the cases showed oblique ligature mark in hanging in which the complete encirclement of the neck was found only in $2 \%$ cases. Comparable data were not found by other workers. It is a well-accepted fact that the ligature mark of hanging and ligature strangulation are not found at the same level. Various authors had reported that ligature mark in 
hanging was situated above the thyroid cartilage level. ${ }^{[1-16]}$ In the cases where suspension was low; the resulting mark may be set at lower level typically immediately above or below the thyroid cartilage. ${ }^{[1,15,17]}$ The gap in the continuity of the ligature mark were observed in $98 \%$ cases of hanging which was closer to the study done by Naik at el $(2005)^{[9]}$ who showed presence of discontinuity in $88.9 \%$ cases of hanging. This fact i.e. discontinuity highly indicating of hanging but is absence neither rules out hanging nor conclude strangulation. ${ }^{[11,17]}$

According to post-mortem interval parchmentisation was found in $56 \%$ cases of hanging followed by reddish brown (23\%) and anemic pale $(21 \%)$. Among 4 cases of ligature strangulation parchmentisation and reddish brown changes were found equally ( 2 cases each). These findings were consistent with previous study by Momanchand et al (1998) $)^{[5]}$. The colour of ligature mark depends largely upon the duration of suspension of the body and nature of the ligature material used.

The abraded epidermis was found in $35 \%$ cases of hanging while dermal congestion was seen in $48 \%$ cases. In case of ligature strangulation dermal hemorrhage $(75 \%)$ was frequent histological finding. Overlapping of one or more histological findings was a common feature. All the section of the skin from hanging and ligature strangulation shows eosinophilic discoloration of the epidermis, which was basophilic in $\mathrm{H} \& \mathrm{E}$ staining. The findings were consistent with the study of Wenyou et al (1991). ${ }^{[18]}$ The hemorrhage in the muscle (sternocleidomastoid) was found in $37 \%$ cases of hanging and 3 cases $(75 \%)$ of ligature strangulation. Since the number of cases of ligature strangulation were less for statistical inference but by mechanism it was strongly suggestive that the hemorrhage in the muscle of the neck under the ligature mark was suggestive of strangulation. Necrosis and autolysis were found in $7 \%$ cases and $9 \%$ cases respectively in hanging. Necrosis was found in one case of accidental ligature strangulation. ${ }^{[13,15,16]}$ The perifollicular congestion and perifollicular hemorrhage were found in hanging while only perifollicular hemorrhage was found in cases of ligature strangulation. Congestion of the cervical lymph node was found in $21 \%$ cases of hanging and in all four (100\%) cases of ligature strangulation. This again signifies that extreme force applied during strangulation. Congestion, hemorrhage and cellular infiltration was not observed in strangulation which proves the point that death in compression of neck is rapid and does not allow the inflammatory mechanism of body to come into action.

\section{Conclusion}

The present study concluded that apart from circumstantial evidences and morphological features in asphyxia deaths histopathological examination of neck structures below ligature mark like epidermis, dermis, connective tissue, muscles etcif undertaken would be more conclusive in establishing the cause and manner of death.

\section{Conflict of Interest: Nil}

\section{References}

1. Camps FE, Robinson AE, Lucas BGB. Gradwohi's Legal Medicine. $3^{\text {rd }}$ ed. Bristol: Johnwright and Sons. 1976. Hypoxia and Asphyxia;p-331-34.

2. Simonsen J. Patho-Anatomic Findings in neck structures in Asphyxiation due to hanging : (A survey of 80 cases). Forensic Science International. 1988;38:83-91.

3. Mallikarjun BS, Dayananda R et al. Study of ligature mark in hanging cases in banglore east region. J.IA.F.M. 2016;1820.

4. Deidiker, Russell D. Accidental ligature strangulation due to a roller type massage device. The American Journal of Forensic Medicine \& Pathology. 1999;20(4):356359. 
5. Momonchand A, Meeradevi T H, Fimate L. Violent asphyxia death in Imphal. Journal of Forensic Medicine \& Toxicology. 1998;15(1):60-64.

6. Khaja S. Fractured Hyoid Bone with Separated Fragment and Type of Fracture. Journal of Indian Academy of Forensic Medicine. 2009.31(1):61-63.

7. Joshi R, Chanana A, Hakumat R. Incidence and medico legal importance of autopsy study od fracture of neck structure in hanging and strangulation. Medico legal Update. 2007.;7(4):105-09.

8. Shrama BR, Harish D, Singh VP. Ligature mark on neck how informative- (A study paper). Journal of Indian Academy of Forensic Medicine. 2005; 27(1): 10.

9. Naik SK. Obliquity v/s Discontinuity of ligature Mark in diagnosis of hanging - (A comparative study). Anil Agarwal's Internet Journal of Forensic Medicine and Toxicology. 2006;7:1.

10. Jani CB, Gupta BD. An Autopsy Study and Parameter Influencing injury to osteocartilaginous structures of neck in hanging. International Journal of Medical Toxicology and Legal Medicine. 2002;5(1):4-7.

11. Knight B. Pressure on the neck. In Simpson's K. Forensic Medicine. $9^{\text {th }}$ ed. ELBS London. 1985:87-105.

12. Parikh CK. Textbook of Medical Jurisprudence, Forensic Medicine and Toxicology. $6^{\text {th }}$ ed. New Delhi: CBS Publishers. 2000. Violent asphyxial deaths. pp-342-48.

13. Reddy KSN. The essentials of Forensic Medicine and Toxicology. $23^{\text {rd }}$ ed. The health sciences publishers. 2014. pp-338364.

14. Pillay VV. A Text Book of Forensic Medicine \& Toxicology. $15^{\text {th }}$ ed. Paras Medical Publisher. 2010. Pp-274-295.
15. Nandy A. Principal's of Forensic Medicine Including Toxicology. $3^{\text {rd }}$ ed. New Central Book Agency Pvt. Ltd. 2010. Pp-320-351.

16. Modi P. Jaising. Textbook of medical jurisprudence and toxicology. $24^{\text {th }}$ ed. Lexis Nevis. 2015. pp-445-467.

17. Williams PL, Bannister LH, Berry MM, Collins P, Dyson M, Dussek JE, Ferguson MWJ. Gray's Anatomy. $38^{\text {th }}$ ed. Churchill Livingstone. 2000. Pp-1094.

18. Wenyou N, Junzhu H, Xinmun Z. A new staining method for constriction maks in skin. Forensic Science International. 1991;50:147-152. 